\title{
Percutaneous coronary intervention in patients with acute coronary syndrome: focus on bivalirudin
}

\author{
Ravi K Ramana \\ Bruce E Lewis \\ Division of Cardiology, Loyola \\ University Medical Center, \\ Maywood, Illinois, USA.
}

Correspondence: Ravi K Ramana

Division of Cardiology, Loyola University Medical Center, Maywood, 2160 South First Avenue, Maywood, ILL 60647, USA

Tel + I 708216.1 I 44

Fax + I 708 327.277|

Email rkramana@earthlink.net

\begin{abstract}
Previously, indirect thrombin inhibitors such as unfractionated heparin or low-molecular-weight heparin were used as a standard anticoagulation during percutaneous coronary intervention to prevent procedural thrombotic complications but at a risk of hemorrhagic complications. More recently, bivalirudin, a member of the direct thrombin inhibitor class, has been shown to have 1) predictable pharmacokinetics, 2) ability to inhibit free- and clot-bound thrombin, 3) no properties of platelet activation, 4) avoidance of heparin-induced thrombocytopenia, and 5) a significant reduction of bleeding without a reduction in thrombotic or ischemic endpoints compared to heparin and glycoprotein IIbIIIa inhibitors when used in patients presenting with acute coronary syndrome who are planned for an invasive treatment strategy.
\end{abstract}

Keywords: bivalirudin, coronary intervention, direct thrombin inhibitor, acute coronary syndrome

\section{Introduction}

Currently, coronary artery disease manifesting as an acute coronary syndrome (ACS) is extremely common, resulting in over 1.5 million hospitalizations in the United States in 2004 (Rosamond et al 2007). With the advancements provided by medical research and medical technology, many of these patients are being evaluated and treated more quickly and more invasively with cardiac catheterization and subsequent percutaneous coronary intervention (PCI). In addition, continued attempts are focused on reducing negative peri-procedural clinical events including ischemia, bleeding, and mortality. Previously, unfractionated heparin (UFH) and low-molecular-weight heparin (LMWH) were used as standard anticoagulation therapy during PCI to prevent procedural thrombotic complications. More recently, direct thrombin inhibitors (DTI) have been evaluated as an anticoagulant in this clinical setting. Bivalirudin (Angiomax ${ }^{\circledR}$, The Medicines Company, NJ) (previously known as Hirulog ${ }^{\circledR}$ ), a member of the DTI class, has been shown to have 1) predictable pharmacokinetics, 2) ability to inhibit free- and clot-bound thrombin, 3) avoidance of platelet activation, 4) avoidance of heparininduced thrombocytopenia (HIT), and 5) a significant reduction of bleeding without a reduction in thrombotic or ischemic endpoints compared to heparin and glycoprotein IIbIIIa inhibitors (GPIIaIIIb inhibitors) when used in patients presenting with ACS.

\section{Pathophysiology of acute coronary syndromes}

The diagnosis of ACS describes a clinical presentation of symptoms that are compatible with acute myocardial ischemia. By definition, ACS includes unstable angina (USA), non-ST-elevation myocardial infarction (NSTEMI), and ST-elevation myocardial infarction (STEMI) (Anderson et al 2007). Most patients who present with 


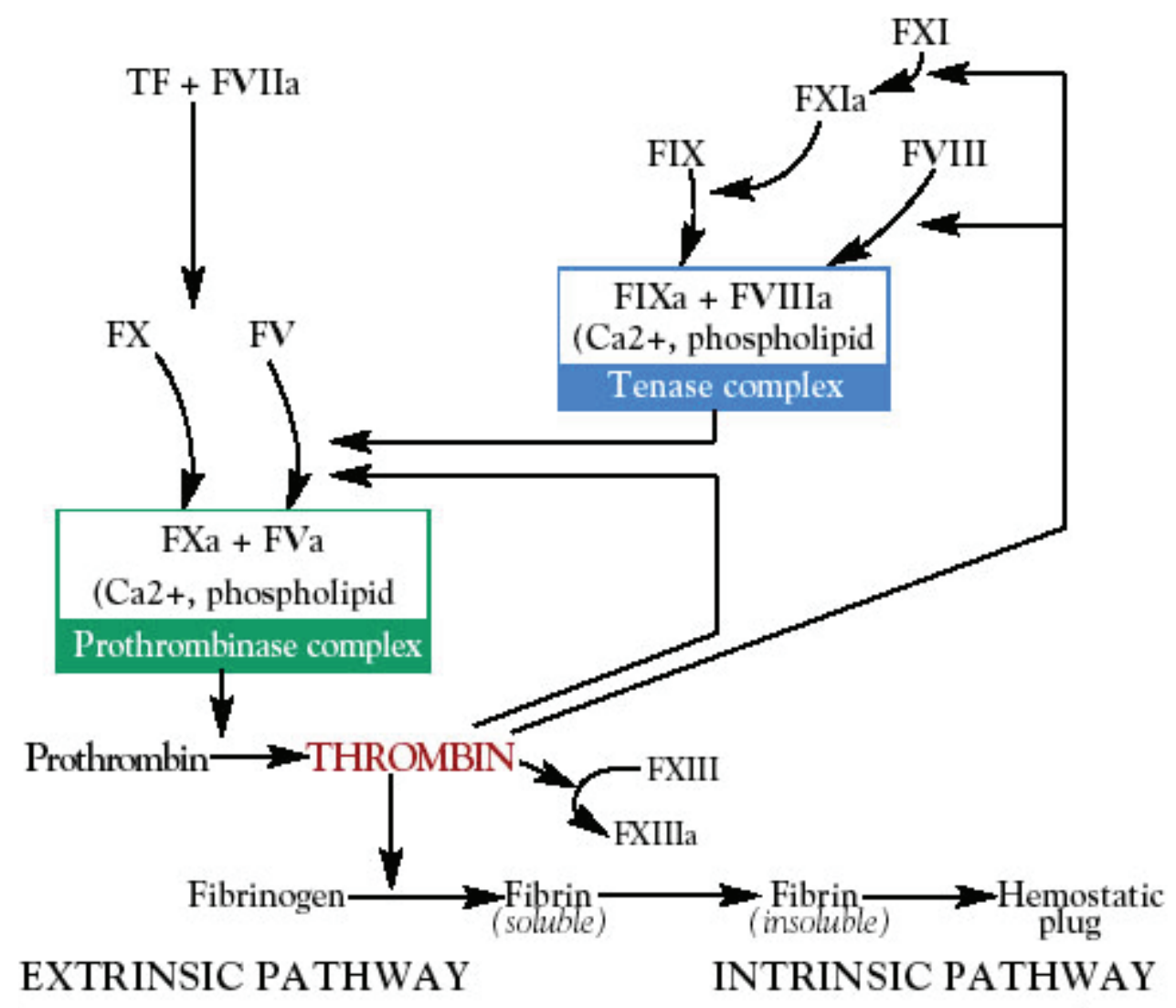

Figure I The coagulation cascade in atherothrombosis. Reprinted with permission from Arora UK, Dhir M. 2005. Direct thrombin inhibitors part I of 2.J Invasive Cardiol, 17:34-8. Copyright () 2005 HMP Communications.

Abbreviations: $\mathrm{F}$, factor; $\mathrm{T}$, tissue.

ACS are hypothesized to be a result of a sudden luminal thrombosis in a epicardial coronary artery (Burke et al 1997, 1998; Virmani et al 2000). This thrombotic process might occur secondary to three differing pathologies: plaque rupture, plaque erosion, or a calcified nodule. The majority of ACS cases are due to plaque rupture (Virmani et al 2006) and therefore will be the focus of the remainder of this review.

The predisposing lesion to plaque rupture is a thin cap fibroatheroma (TCFA) or "vulnerable plaque" which is characterized by a necrotic core, an overlying thin fibrous cap $(<65 \mu \mathrm{m})$ which contains a dense concentration of macrophages ( $>25 / \mathrm{hpf}$ ) and few smooth muscle cells (Schaar et al 2004). As a result of external (eg, shear stress) and internal forces (ie, enzymatic and degradation active processes within the plaque), the fibrous cap ruptures allowing direct contact between the highly thrombogenic necrotic core and circulating platelets and monocytes. These circulating platelets adhere to and become activated by the exposed subendothelial components, most notably collagen and von Willebrand factor (vWF). Following activation, these platelets release chemoattractants (eg, adenosine diphosphate and thromboxane A2) which promote further platelet adhesion to the site of endothelial injury. In addition, activated macrophages and smooth muscle cells from the exposed necrotic core release tissue factor (TF) leading to activation of the coagulation cascade (Arora and Dhir 2005) and thrombin production (Sciulli and Mauro 2002). Thrombin binds to fibrin particles and continues to strongly activate platelets (Kumar et al 1995); activate Factors V, VIII, and XIII (which further stimulate thrombin production and stabilize the fibrin-bound thrombin) (Kumar et al 1994; Sciulli and Mauro 2002); convert fibrinogen to fibrin (Weitz et al 1990); and activate carboxypeptidase B, a known fibrinolysis inhibitor (Sakharov et al 1997; Fenton et al 1998). The fibrin-bound thrombin (or fibrin split product-bound thrombin) remains enzymatically active and is protected from degradation by fluid-phase inhibitors (Weitz et al 1990, 1998).

Previous research has suggested that there are three receptor sites on thrombin: one active catalytic and two exosites (Hogg and Bock 1997; Becker et al 1999) (Figure 2). The catalytic site plays a role in the conversion of fibrinogen to 


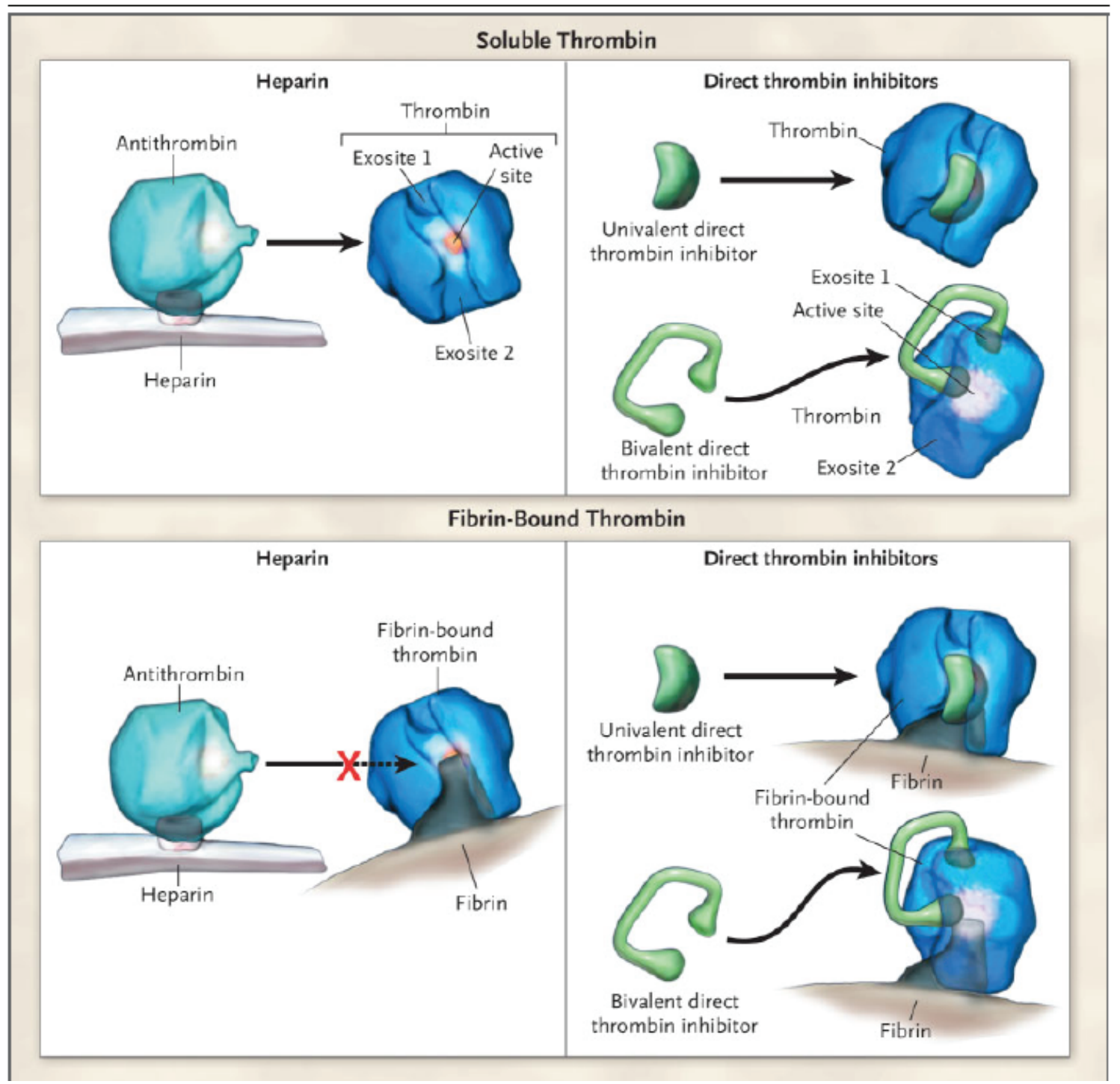

Figure 2 Bivalirudin's action on thrombin. Reprinted with permission from Di Nisio M, Middeldorp S, Buller HR. 2005. Direct thrombin inhibitors. N Engl J Med, 353: $1028-40$. Copyright $\odot 2005$ Massachusetts Medical Society. All rights reserved.

fibrin and further activation of platelets and clotting factors (Sciulli and Mauro 2002). Exosites 1 and 2 are positively charged and therefore bind negatively charged compounds: fibrinogen and heparin-antithrombin complex, respectively. Cleavage of fibrinogen occurs over the catalytic site after the fibrinogen particle aligns itself with exosite 1. Following cleavage, although the fibrin monomer may remain attached to exosite 1, the thrombin's active site remains free to initiate further catalytic processes (Hogg and Bock 1997; Fenton et al 1998). In contrast, when a heparin-antithrombin complex nears free thrombin, it is theorized that the heparin subunit binds to exosite 2 and the antithrombin (AT) subunit attaches to the active site resulting in deactivation of the freethrombin. However, when a heparin-antithrombin complex nears fibrin-bound thrombin and the heparin subunit binds to exosite 2, there is a conformational change that occurs at thrombin's active site resulting in a decreased ability for the AT subunit to bind and inactivate the active site (therefore, leaving thrombin enzymatically active) (Hogg and Bock 1997 Fenton et al 1998).

\section{Anticoagulation therapy for ACS}

In patients presenting with $\mathrm{ACS}$, it is imperative to modify the underlying pathophysiology of plaque rupture and thrombosis in attempt to reduce the likelihood of myocardial infarction (MI) and death. This is most effectively achieved with a combination of antiplatelet (eg, aspirin or GPIIbIIIa inhibitors) and anticoagulant medications 
(Anderson et al 2007). Because platelets are a prominent mediator in thrombus formation after plaque rupture, it is not surprising that studies regarding patients presenting with ACS and comparing aspirin with placebo have consistently shown a dramatic benefit in reduction of MI, stroke, death, and other major cardiac endpoints (Lewis et al 1983; Cairns et al 1985; ISIS-2 1988; Theroux et al 1988; RISC 1990). Other forms of antiplatelet medications such as ADP receptor (P2Y12) antagonists (eg, clopidogrel) have been shown to reduce similar adverse outcomes when used alone or especially when used in conjunction with aspirin (Schror 1993; CAPRIE 1996; Mehta et al 2001; Yusuf et al 2001).

Also, anticoagulants are necessary to prevent thrombus propagation or even possibly lyse existing thrombus. Several randomized trials comparing aspirin (ASA) alone versus UFH with ASA revealed an approximate $33 \%-50 \%$ reduction in short-term (but not long-term) rates of MI or death (Telford and Wilson 1981; Williams et al 1986; Theroux et al 1988, 1993; Cohen et al 1994; Oler et al 1996; Yusuf et al 2001). Studies evaluating the addition of LMWH (eg, nadroparin, dalteparin, enoxaparin) to ASA therapy in ACS patients report significant reductions in MI, stroke, and need for re-revascularization procedures (Gurfinkel et al 1995; FRISC 1996), but possibly at a cost of higher rates of major and minor bleeding in those patients treated with an early invasive strategy (Ferguson et al 2004).

Until recently, heparin has been nearly universally used as the systemic anticoagulant of choice in the treatment of ACS and during PCI. Heparin acts via binding and catalyzing the activity of AT. The heparin-AT complex in turn equally inhibits the activity of Factor Xa and IIa (thrombin) (Hirsh 1991; Sciulli and Mauro 2002). In addition, UFH inhibits thrombin by simultaneously binding to AT and keeping these two molecules in proximity of one another (Hirsh 1991). It is important to note that heparins do not inhibit thrombin bound to fibrin, thrombin bound to fibrin degradation products, or Factor Xa bound to platelets (Mirshahi et al 1989; Furie and Furie 1992; Hogg and Bock, 1997). In addition, heparin binds to endothelial cells and a number of plasma proteins which limits its availability to interact with $\mathrm{AT}$ and therefore reduces its potential anticoagulant effect (Da 1989; de Romeuf and Mazurier 1993). In slight contrast, LMWH chains are not long enough to bridge thrombin to AT, which therefore leads to more Factor Xa inhibition than thrombin inhibition (Weitz 1997). UFH and LMWH can be inactivated by platelet factor 4 (PF4) (Eitzman et al 1994) and the subsequent UFH(LMWH)-PF4 complex may act as a source of immunoglobin G mediated HIT (HIT Type II) (Chong 2003; Lehman and Chew 2006). Therefore, because of its non-specific binding to endothelium and plasma proteins, heparin's half-life is dose dependent and anticoagulant's bioavailability and effects have high intra- and inter-patient variability.

These obvious limitations of these heparin compounds have driven the research and development of other antithrombotic agents. One newer class of anticoagulants, Factor Xa inhibitors, were investigated in the Organization for the Assessment of Strategies for Ischemic Syndromes (OASIS) 5 and Trials. These trials compared fondaparinux with standard UFH or LMWH strategies in patients presenting with USA/NSTEMI. Short-term combined outcomes of death, MI, or refractory ischemia was similar in the two groups (5.8\% vs $5.7 \%, \mathrm{p}=\mathrm{NS}$ ) with significantly less bleeding in the fondaparinux $\operatorname{arm}(2.2 \%$ vs $4.1 \%, p \leq 0.001)$. However, at 180 days, fondaparinux was associated with significant reductions in death, MI and stroke, but with an increased risk of catheter-associated thrombus at the time of PCI $(0.9 \%$ vs $0.3 \%$ ). Therefore, it has been recommended that patients who received fondaparinux prior to PCI also receive another anti-Factor IIa (eg, UFH) to support PCI (Yusuf et al 2006a, b; Anderson et al 2007).

Another class of anticoagulants for the treatment of arterial thrombosis is direct thrombin inhibitors. The class of DTIs include hirudin and its synthetic derivative (eg, bivalirudin), molecules that react with the active-site of thrombin (eg, Phe-Pro-Arg-chloromethylketone [PPACK], argatroban, melagatran, and ximelagatran), and thrombinbinding DNA aptamers. The biologic activity of DTIs, unlike those of heparin, is independent of the presence of antithrombin as they act directly on the thrombin molecule. Bivalent DTIs (hirudin, lepirudin, desirudin, and bivalirudin) interact with the active site and exosite 1 of thrombin, whereas univalent DTIs (argatroban) bind only to the active site (Di Nisio et al 2005). Although these three classes work with differing mechanisms, they all present advantages over heparin including: 1) the ability to inactivate fibrin-bound thrombin, 2) they do not bind to endothelial cells or plasma proteins, and 3) they have improved predictability of pharmacokinetics (Arora and Dhir 2005).

For the purposes of this review, only bivalirudin will be discussed in detail. Of note when compared to hirudin, bivalirudin has a wider therapeutic window (allowing less laboratory monitoring) and wider safety margin (allowing the 
administration of higher doses which may result in greater availability/inhibition of thrombin and thrombomodulin) (Bittl 1995).

\section{Pharmacology of bivalirudin Mechanism of action}

Bivalirudin is a semi-synthetic 20 amino-acid polypeptide derived from native hirudin (Maraganore et al 1990) (Figure 3). This compound is specific for thrombin, binds at a $1: 1$ ratio with thrombin, is active against unbound and bound thrombin, is not inactivated by PF4, and does not require any cofactors for activity (Bates and Weitz 1998; Sciulli and Mauro 2002). The amino-terminal segment has a high affinity and specificity for binding to thrombin's active site and the carboxy-terminal segment binds to exosite 1 . Bivalirudin acts by direct competitive inhibition with fibrinogen to exosite 1 and the active site which results in complete inhibition of fibrin formation and catalytic function (Maraganore et al 1990). The binding is reversible as thrombin slowly cleaves bivalirudin near the amino-terminal end resulting in separation of the amino-terminal from the active site (Parry et al 1994). As a result of this detachment, the carboxy-terminal affinity to exosite 1 is weakened and bivalirudin may be displaced altogether from the thrombin by a fibrinogen particle (Parry et al 1994) (Figure 3).

\section{Pharmokinetics and pharmacodynamics}

Previous research has shown that bivalirudin appears to have very predictable, linear pharmacokinetic properties. Peak plasma concentrations following bolus infusions occurred within 5 minutes (Fox et al 1993) and steady-state concentrations during continuous infusions were directly related to dose (Lidon et al 1993; Angiomax Product Information 2000). Bivalirudin has been shown to have linear pharmacokinetics with rapid plasma clearance $(3 \mathrm{~mL} / \mathrm{min} / \mathrm{kg}$ ) and a small volume of distribution (0.2 L/kg) (Bates 2004). Although the anticoagulant effects of bivalirudin may slightly vary between patients, there is very little variability once a response to a dose is given. Specifically, previous studies have shown that the anticoagulant effects of bivalirudin are directly related to dose: prothrombin time (PT), activated partial thromboplastin time (aPTT), thrombin time (TT), and activated clotting time (ACT) all rise linearly with an increase in dose (Cannon et al 1993; Fox et al 1993; Lidon et al 1993; Topol et al 1993; Sharma et al 1993). These anticoagulant properties occur within minutes of an intravenous bolus injection and return to baseline approximately 1 hour after infusion is discontinued in patients with normal healthy patients (Fox et al 1993; Angiomax Product Information 2000). In addition, there is no evidence that bivalirudin binds to non-thrombin plasma proteins, and it is cleared by (predominantly) renal elimination and intravascular proteolysis (Angiomax Product Information 2000; Robson 2000; Reed and Bell 2002). It has been shown that compared to normal healthy patients, bivalirudin clearance is approximately half in hospitalized patients with normal renal function (creatinine clearance greater than $60 \mathrm{~mL} / \mathrm{min}$ ), nearly $40 \%$ in patients with creatinine clearance between 10 and $60 \mathrm{~mL} / \mathrm{min}$, and $10 \%$ in patients requiring hemodialysis (Angiomax Product Information 2000; Robson 2000). As a result, the plasma halflife of bivalirudin is 22 minutes, 34 minutes, and 210 minutes in patients with normal renal function (creatinine clearance greater than $60 \mathrm{~mL} / \mathrm{min}$ ), moderate renal dysfunction, and on hemodialysis, respectively (Angiomax Product Information 2000; White 2001). Therefore, in clinical scenarios involving severe renal dysfunction, the recommendation is to maintain the standard bolus dosing and reduce the infusion rate to $1 \mathrm{mg} / \mathrm{kg} /$ hour if the creatinine clearance less than $30 \mathrm{~mL} /$ minute or $0.25 \mathrm{mg} / \mathrm{kg} /$ hour if the patient is on hemodialysis. Currently, there is no antidote to counteract the anticoagulants effects (Bates 2004). Current dosage recommendations have been made (Table 1).

Bivalirudin's anticoagulant effects are not affected by concurrent aspirin use (Fox et al 1993). Importantly,

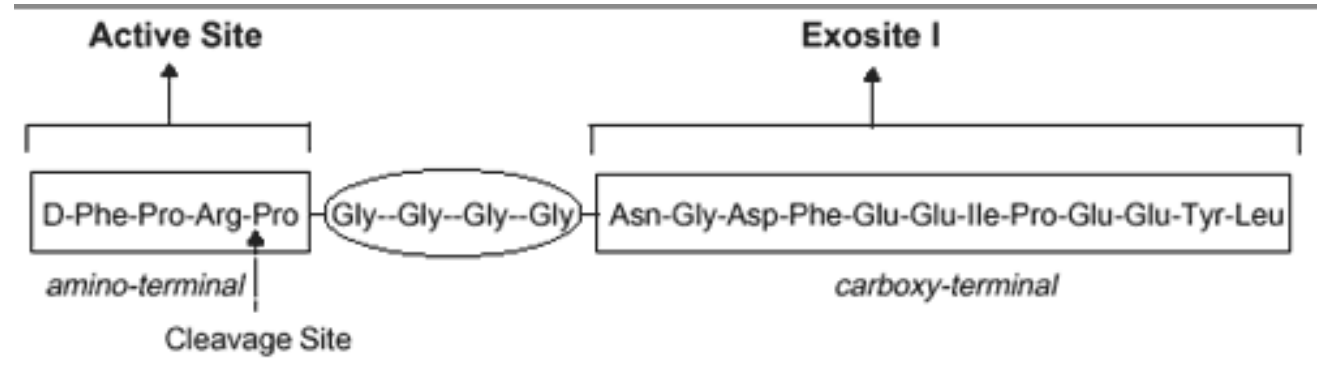

Figure 3 Structure of bivalirudin. Reprinted with permission from Sciulli TM, Mauro VF. 2002. Pharmacology and clinical use of bivalirudin. Ann Pharmacother, 36: I028-4I. Copright (C) 2002 Harvey Whitney Books Co. 
Table I Current dosage recommendations for bivalirudin for various patient subpopulations

\begin{tabular}{lll}
\hline Patient subgroup & $\begin{array}{l}\text { Initial bolus } \\
(\mathbf{m g} / \mathbf{k g})\end{array}$ & $\begin{array}{l}\text { Infusion during } \\
\mathbf{P C l}(\mathbf{m g} / \mathbf{k g} / \mathbf{h r})\end{array}$ \\
\hline $\begin{array}{l}\text { Normal renal function } \\
\left(>90 \mathrm{~mL} / \mathrm{min}^{\mathrm{a}}\right)\end{array}$ & 0.75 & 1.75 \\
$\begin{array}{l}\text { Mild renal impairment } \\
\left(60-90 \mathrm{~mL} / \mathrm{min}^{\mathrm{a}}\right)\end{array}$ & 0.75 & 1.75 \\
$\begin{array}{l}\text { Moderate renal impairment } \\
\left(30-59 \mathrm{~mL} / \mathrm{min}^{\mathrm{a}}\right)\end{array}$ & 0.75 & 1.75 \\
$\begin{array}{l}\text { Severe renal impairment } \\
\left(10-29 \mathrm{~mL} / \mathrm{min}^{\mathrm{a}}\right)\end{array}$ & 0.75 & 1.00 \\
$\begin{array}{l}\text { Dialysis-dependent } \\
\text { HIT/HITTS undergoing PCI }\end{array}$ & 0.75 & 0.75 \\
\hline
\end{tabular}

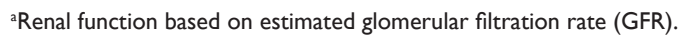

Abbreviations: HIT/HITTS, heparin-induced thrombocytopenia/heparin-induced thrombocytopenia with thrombotic syndrome; $\mathrm{PCl}$, percutaneous coronary intervention.

research evaluating the direct platelet effects of therapeutic concentrations of bivalirudin (compared to UFH or LMWH) have shown bivalirudin did not activate platelets (see Figure 4), decreased platelet surface coverage, attenuated platelet attachment to injured endothelium, and reduced SCD40L (a marker of inflammation) in healthy and in patients undergoing PCI (Topol et al 1993; Shen et al 1997; Anand et al 2007). In addition, there is a dosedependent relationship between bivalirudin and a decrease in plasma concentrations of fibrinopeptide A (a marker of fibrinogen conversion) (Topol et al 1993) and inhibition of plasminogen activator inhibitor activity (Shen et al 1997). Therefore, bivalirudin has a more predictable anticoagulation response among treated patient population. Of note, lepirudin's binding to thrombin is irreversible and argatroban binds only reversibly to thrombin's active site (Bates and Weitz 1998).

According to initial trials, the most common reported adverse effects of bivalirudin were back pain, nausea, headache, and hypotension. Less frequently reported reactions ( $<10 \%$ of cases) include insomnia, hypertension, vomiting, anxiety, dyspepsia, bradycardia, abdominal pain, fever, nervousness, and pelvic pain (Topol et al 1993). These complaints did not occur at a higher rate when compared to patients receiving heparin therapy. There has been no data that suggests there are any effects on reproductive parameters, teratogenicity, mutagenicity, or antigenic/immunogenic response (Bates 2004). Any explained drop in blood pressure or hematocrit should be assessed with an expedited work-up for bleeding or hemorrhage. There has been no reported associated with bivalirudin and thrombocytopenia. In addition, bivalirudin is contraindicated in patients with active major bleeding or hypersensitivity to the drug or its components (Angiomax Product Information 2000).

\section{Clinical trials}

There has been an extensive amount of in vitro and clinical research investigating the safety and efficacy of bivalirudin which has led to its current clinical indications for use in ACS patients (Table 2).

\section{Unstable angina or NSTEMI patients}

The initial study to assess the efficacy and appropriate dosing with a DTI (Hirulog) as a sole anticoagulant in patients undergoing coronary angioplasty (POBA) was reported in 1993. This multi-center trial enrolled 291 patients undergoing POBA who received an intravenous bolus followed by continuous infusion of Hirulog for 4 hours following the procedure. Several dosing strategies were used and coagulation and hematologic variables were measured throughout the therapy. The primary endpoint of abrupt vessel closure occurred in $6.2 \%$ of patients; no significant bleeding complications were noted in any patients; and a more predictable, dose-response curve of both ACTs and aPTTs was seen. This study was the first to report that it was possible to safely perform POBA with an anti-coagulant other than heparin in aspirin-pretreated patients (Topol et al 1993).

The first randomized comparisons of bivalirudin versus heparin in patients undergoing coronary intervention were reported in HAS Trial and the Bivalirudin Angioplasty Trial (BAT) - these two trials used the same patient database but differing methods of analysis. These studies randomized 4,312 patients to heparin or bivalirudin immediately before POBA for unstable or post-infarction angina. Investigators stated the primary endpoint was combined death in the hospital, abrupt vessel closure, or "rapid clinical deterioration of cardiac origin" requiring emergent coronary artery bypass surgery (CABG), intra-aortic balloon counterpulsation (IABP), or repeated POBA. The results indicated that there was no significant difference between the two groups in combined primary endpoint (11.4\% bivalirudin vs $12.2 \%$ heparin-arm), but did result in a lower incidence of bleeding $(3.8 \%$ vs $9.8 \%, p<0.001)$. More specifically, in the patients undergoing POBA for post-infarction angina, the use of bivalirudin resulted in a lower incidence of combined primary endpoint $(9.1 \%$ vs $14.2 \%, \mathrm{p}=0.04)$ and a lower incidence of bleeding ( $3 \%$ vs $11 \%, \mathrm{p}<0.001)$ (Bittl et al 1995). Following the BAT analysis, a FDA-endorsed re-analysis based on an intention-to-treat analysis confirmed these findings. Specifically, bivalirudin was at least as effective 

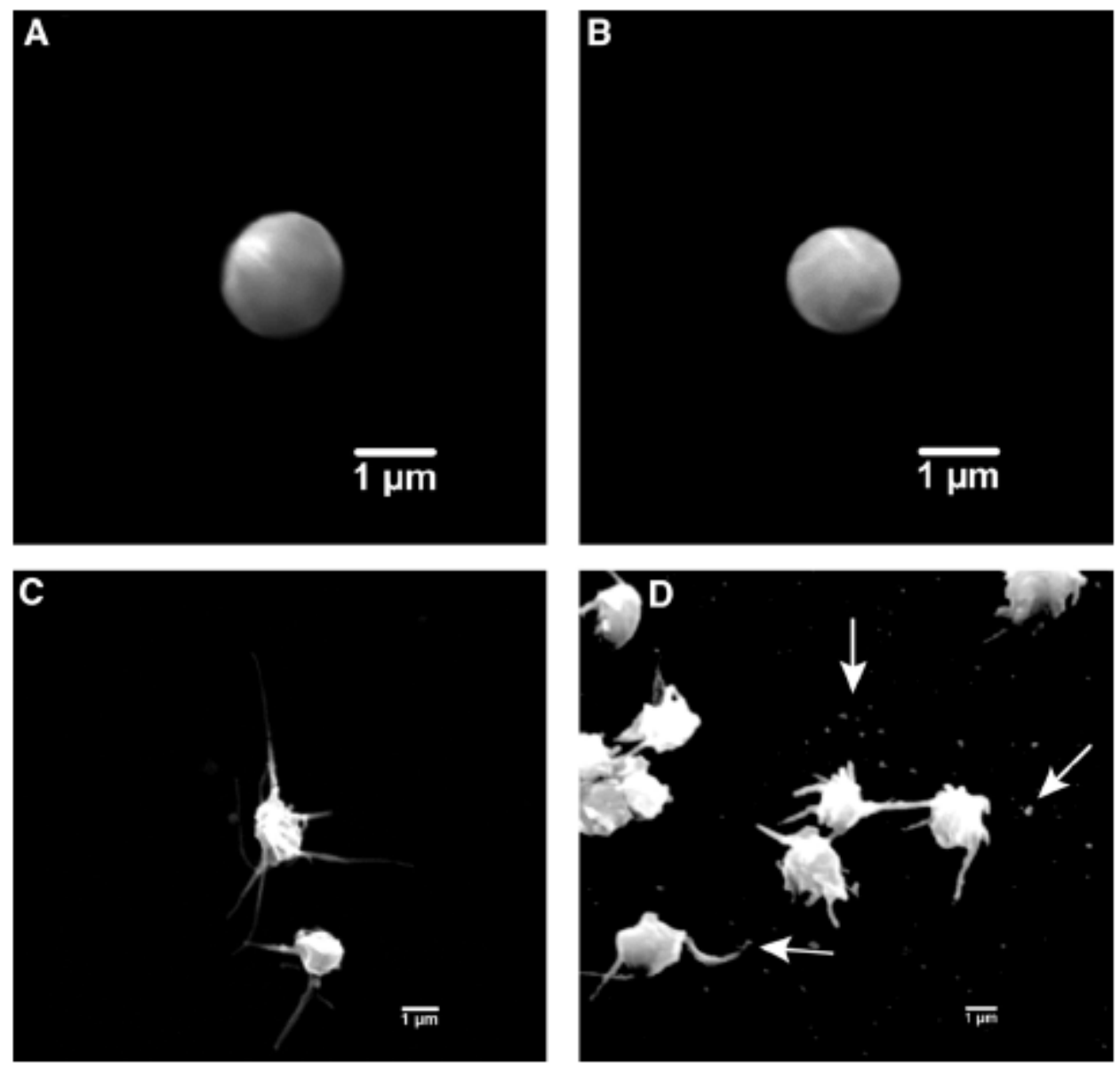

Figure 4 Scanning electron photomicrographs representing differences in platelet activation between anticoagulants. (A) normal platelet at rest, (B) platelet response to bivalirudin therapy, (C) platelet response and activation with UFH therapy, (D) platelet response (release of microparticles) after UFH therapy. Reprinted with permission from Anand SX, Kim MC, Kamran M, et al. 2007. Comparison of platelet function and morphology in patients undergoing percutaneous coronary intervention receiving bivalirudin versus unfractionated heparin versus clopidogrel pretreatment and bivalirudin. Am J Cardiol, 100:417-24. Copyright @ 2007 Elsevier.

in preventing death, MI, or need for revascularization at 180 days $(23.0 \%$ vs $24.7 \%, p=0.153)$, but with fewer major bleeding complications ( $3.7 \%$ vs $9.3 \%, p=<0.001)$. These findings were consistent among patients undergoing angioplasty for either unstable angina or post-infarction angina (Bittl et al 2001).

Another study, TIMI-8, attempted to compare the efficacy and safety of low-dose bivalirudin versus UFH in patients presenting with USA/NSTEMI. 133 patients were randomized (prior to early termination of the trial), and results suggested a trend towards less combined nonfatal MI or death or major hemorrhage at 14 days in patients receiving bivalirudin (2.9\% vs 9.2\%, 0\% vs 4.6\%, respectively) (TIMI-8 2002).

With the introduction of coronary stents, clopidogrel, and GPIIb/IIIa inhibitors use in PCI, bivalirudin was tested in the Comparison of Abciximab Complications with Hirulog for Ischemic Events Trial (CACHET) and the Randomized Evaluation in PCI Linking Angiomax to Reduced Clinical
Events Trials (REPLACE-1 and REPLACE-2). First, CACHET, a pilot trial of 268 patients undergoing PCI, compared the use of bivalirudin (at varying doses) with and without abciximab versus standard UFH therapy with abciximab. The results of CACHET suggested that bivalirudin with planned or provisional abciximab appeared to be as safe and effective as standard UFH plus abciximab in these patients undergoing PCI (Lincoff et al 2002).

Subsequently, the REPLACE trials were conducted among patients undergoing urgent or elective PCI with nearly $85 \%$ of patients receiving clopidogrel before the procedure and stent implantation during the procedure. REPLACE-1 was a pilotstudy that showed that bivalirudin use in contemporary PCI trended to less ischemic and bleeding outcomes (Lincoff et al 2004). This allowed further investigation in REPLACE-2, which randomized 6,010 patients to receive UFH (65 U/kg) plus abciximab (Reopro ${ }^{\circledR}$, Centocor Inc., PA, USA) or eptifibatide (Integrillin ${ }^{\circledR}$, Millenium Pharmaceuticals, Inc, 
Table 2 Guideline-based indications for the use of bivalirudin in ACS patients (Anderson et al 2007; King et al 2007)

\begin{tabular}{|c|c|c|}
\hline Clinical setting & Description & ACC/AHA indication \\
\hline HIT/HITTS & $\begin{array}{l}\text { For patients with known HIT/HITTS and } \\
\text { undergoing } \mathrm{PCl} \text { or CABG. }\end{array}$ & Class I \\
\hline \multirow[t]{4}{*}{ USA/NSTEMI } & $\begin{array}{l}\text { For patients in whom an invasive strategy is selected, } \\
\text { bivalirudin is started upon hospital presentation. }\end{array}$ & Class I, LOE B \\
\hline & $\begin{array}{l}\text { For patients in whom } \mathrm{PCl} \text { has been selected as a post-angiography } \\
\text { management strategy, bivalirudin is used with at least } 300 \mathrm{mg} \text { of } \\
\text { clopidogrel administered at least } 6 \mathrm{~h} \text { earlier. }\end{array}$ & Class Ila, LOE B \\
\hline & $\begin{array}{l}\text { For patients in whom PCI has been selected as a post-angiography management } \\
\text { strategy, bivalirudin is used with a GPIlbllla inhibitors if } \\
\text { at least } 300 \mathrm{mg} \text { of clopidogrel was NOT administered at least } 6 \mathrm{~h} \text { earlier. }\end{array}$ & Class Ila, LOE B \\
\hline & $\begin{array}{l}\text { For patients in whom a conservative strategy is selected, bivalirudin is } \\
\text { started upon hospital presentation. }\end{array}$ & No current recommendation. \\
\hline \multirow[t]{2}{*}{ STEMI } & $\begin{array}{l}\text { For patients undergoing primary } \mathrm{PCl} \text { or Rescue } \mathrm{PCl} \text {, bivalirudin is started } \\
\text { prior to intervention. }\end{array}$ & No current recommendation. \\
\hline & $\begin{array}{l}\text { For patients undergoing primary } \mathrm{PCl} \text { or Rescue } \mathrm{PCl} \text { who have received UFH } \\
\text { up to the time of intervention, bivalirudin is used during the intervention. }\end{array}$ & Class I, LOE C \\
\hline
\end{tabular}

Abbreviations: ACC/AHA,American College of Cardiology/American Heart Association;ACS, acute coronary syndrome; CABG, coronary artery bypass surgery; HIT/HITTS, heparin-induced thrombocytopenia/heparin-induced thrombocytopenia with thrombotic syndrome; $\mathrm{PCl}$, percutaneous coronary intervention; STEMI, ST-elevation myocardial infarction; NSTEMI, non-ST-elevation myocardial infarction; USA, unstable angina.

MA, USA) for $12-18$ hours or bivalirudin $(0.75 \mathrm{mg} / \mathrm{kg}$ bolus with $1.75 \mathrm{mg} / \mathrm{kg} /$ hour infusion during the procedure) with provisional GPIIb/IIIa inhibitors use available for "bail-out" purposes (defined as abrupt vessel closure, obstructive dissection, new or suspected thrombus, slow coronary flow, distal embolization, persistent residual stenosis, unplanned stent placement, prolonged ischemia, or other clinical instability). The primary endpoint of composite death, MI, severe ischemia requiring repeat revascularization, or inhospital major bleeding within 30 days of randomization revealed no significant difference between the two patients groups $(9.2 \%$ bivalirudin vs $10 \%$ GPIIb/IIIa inhibitors, $\mathrm{p}=0.32)$. However, there was less major bleeding $(2.4 \%$ vs $4.1 \%, \mathrm{p}=0.001)$ and thrombocytopenia $(0.7 \%$ vs $1.7 \%$, $\mathrm{p}=0.001)$ in those patients initially treated with bivalirudin. Although there was no significant difference in mortality at 12 month follow-up, there were patient subgroups that seemed to have a strong trend towards a reduction in mortality: elderly over 75 years of age, diabetics, renal insufficiency (as defined as a creatinine clearance less than $60 \mathrm{~mL} / \mathrm{min}$ ), unstable angina, or any previous heparin therapy (Lincoff et al 2003).

In 2006, the PROTECT-TIMI-30 study reported on its investigation comparing eptifibatide plus UFH or LMWH versus bivalirudin alone in 857 patients presenting with ACS and undergoing PCI. This trial randomized patients into three treatment arms: bivalirudin alone, eptifibatide plus reduced-dose UFH or eptifibatide plus reduced-dose LMWH. Although the null hypothesis was to show that coronary flow reserve after PCI was better with eptifibatide, the results actually showed that bivalirudin was associated with higher coronary flow reserve following PCI. Secondary endpoint analysis suggested that patients undergoing PCI who were randomized to eptifibatide experienced improved Thrombolysis In Myocardial Infarction (TIMI) myocardial perfusion grade following PCI, shorter duration of ischemia on continuous Holter monitoring after PCI, more minor bleeding events, a higher transfusion rate, and no difference in biomarkers for myonecrosis, inflammation, and thrombin generation (Gibson et al 2006).

More recently, guidelines have recommended an early invasive strategy for patients presenting with moderate- or high-risk ACS in conjunction with aggressive antiplatelet, antithrombotic medications (Anderson et al 2007). In these patients, the use of bivalirudin as an anticoagulant was extensively evaluated in the Acute Catheterization and Urgent Intervention Triage Strategy (ACUITY) Trial. This prospective, randomized trial compared UFH plus GPIIbIIIa inhibitors, bivalirudin plus GPIIbIIIa inhibitors, and bivalirudin alone in over 13,000 patients. Outcomes at 30 days revealed non-inferior rates of composite ischemic endpoint (death, MI, unplanned revascularization) $(7.3 \%$ vs $7.8 \%$, respectively, $\mathrm{p}=\mathrm{NS}$ ), but a significant reduction in major bleeding and net clinical outcomes endpoint (defined as combined composite ischemia and major bleeding) (3.0\% vs 5.7\%, $\mathrm{p}<0.001$, and $10.1 \%$ vs $11.7 \%, \mathrm{p}=0.02$ ) in patients who received bivalirudin alone compared to UFH plus GPIIbIIIa inhibitors. Similarly, outcomes at 1 year reported no signifi- 
cant difference in the composite ischemic endpoint $(15.4 \%$ vs $16.2 \%, p=0.29)$ or overall mortality $(3.8 \%$ vs $3.9 \%$, $\mathrm{p}=0.62$ ) between the same two groups. Further multivariate analysis revealed that predictors of mortality at 1 year were major bleeding event(s) at 30 days (HR 2.89, CI 2.24-3.72, $\mathrm{p}<0.0001)$ and/or MI (HR 2.47, CI 1.87-3.27, p < 0.0001) (Stone et al 2006, 2007a).

Subsequent analysis investigated the 7,789 patients from the ACUITY trial who underwent PCI. Thirty-day endpoints of composite ischemia or net clinical outcomes were not different between the groups; however there was still significantly less bleeding in the bivalirudin alone group compared to patients receiving UFH plus GPIIbIIIa inhibitors (3.5\% vs $6.8 \%, \mathrm{p}<0.0001)$. Of note, in patients who were troponin-positive at the time of PCI, there were no significant difference in rates of ischemic complications in the between the treatment groups (but an absolute 1\% increase in ischemic endpoints in the bivalirudin-alone group). In addition, in patients who had received clopidogrel loading prior to their PCI, rates of 30-day ischemic events and overall reduction in combined net clinical outcomes were similar between the bivalirudin-alone and UFH plus GPIIbIIIa inhibitors groups $(8.1 \%$ vs $8.4 \%, p=$ NS and $11.1 \%$ vs $13.8 \%, p=N S$ ) (Stone et al 2007b). These robust data resulted in a Class I indication for the use of bivalirudin in patients presenting with USA/NSTEMI (Anderson et al 2007).

Of note, one study reported the safety and efficacy of using bivalirudin during PCI requiring rotational atherectomy (RA) in patients presenting for elective or emergent revascularization. This smaller, single-center study reviewed 253 cases, 56 of whom were treated with bivalirudin during their $\mathrm{RA}$ procedure, and reported no difference in the incidence of any myonecrosis as measured by elevated CK-MB postprocedure (Gurm et al 2007).

\section{HIT/HITTS patients}

Up to $5 \%$ of patients given heparin develop HIT or HIT with thrombotic syndrome (HITTS). Initial case reports of the safety and efficacy of using hirolug in the setting of POBA in patients with HIT/HITTS were published in 1995 (Chamberlin et al 1995). Since that time, further investigation (ATBAT trial) was conducted in a prospective, single-arm study evaluating the safety and efficacy of bivalirudin in patients undergoing PCI with newly diagnosed or previous HIT/HITTS. In this trial, 52 patients were identified and received bivalirudin during and up to 4 hours following the PCI procedure. The primary endpoint was major bleeding prior to discharge. The investigators reported no major bleeding events in any patient undergoing PCI (one major bleeding event in a patient who underwent elective $\mathrm{CABG}$ ) or need for transfusion. More importantly, there was no significant thrombocytopenia observed in the 52 patients following PCI after administration of bivalirudin. These data supported bivalirudin's Class I indication for use in patients with or at high-risk of HIT/HITTS during treatment for ACS or undergoing PCI (Mahaffey et al 2003; Anderson et al 2007).

\section{STEMI patients}

Initial investigation for the use of bivalirudin for patients presenting with STEMI and undergoing PCI was reported in the HERO-2 Trial. This study evaluated the efficacy of using bivalirudin in conjunction with standard thrombolytic (streptokinase) therapy (versus standard UFH+streptokinase) in over 17,000 STEMI patients. At 30 days, comparison between the two groups revealed no significant difference in overall mortality, but patients randomized to bivalirudin therapy experienced significantly less reinfarction within 96 hours of presentation (RR 0.70, CI 0.56-0.87, $\mathrm{p}=0.001$ ) (White 2001).

Further investigation for the use of bivalirudin in patients presenting with STEMI undergoing PCI was reported in the BiAMI Trial. Presented in 2006, this prospective, single-arm study treated patients presenting with STEMI to standarddosing bivalirudin infusion for the duration of the procedure, with abciximab used only if TIMI 3 flow was not established post-stenting. Event rates at 1 month reported that bivalirudin provided comparable ischemic protection with fewer bleeding complications (compared to previously reported UFH plus inhibitors IIb/IIIa data) (Stella et al 2004, 2006).

In 2007, the Harmonizing Outcomes with Revascularization and Stents in Acute Myocardial Infarction (HORIZONS AMI) was presented. This trial randomized over 3,600 patients presenting with STEMI to UFH plus GPIIb/IIIa inhibitors or to bivalirudin monotherapy with provisional GPIIb/IIIa inhibitors for large thrombus or refractory noflow. At 30 days, there was a significant $24 \%$ reduction in net clinical events (defined as combined death, MI, ischemia requiring repeat-revascularization, stroke, or major bleeding) and a $40 \%$ reduction in major bleeding. In addition, patients in the bivalirudin monotherapy arm had lower rates of cardiac mortality $(1.8 \%$ vs $2.9 \%, \mathrm{p}=0.035)$, but higher rates of acute stent thrombosis in the first 24 hours post-PCI $(0.3 \%$ vs $1.3 \%$, $\mathrm{p}=0.0009$ ) (Stone 2007).

It is important to note that for several of these studies there was post-hoc analysis investigating whether a 
hazard existed if UFH or LMWH was administered prior to the study medication (bivalirudin). The SWITCH trial, in which ACS patients were treated with LMWH and switched (at varying time interval prior to the procedure) to bivalirudin for PCI, showed that switching from LWMH to bivalirudin was not associated with an increase in major bleeding regardless of the time from last dose of LMWH (Waksman et al 2006). Later, analysis from REPLACE-2 showed that there was no significant difference in major or minor bleeding in patients who were randomized to bivalirudin after receiving UFH or LMWH when compared to those patients who were not treated with any heparinoid medication prior to randomization. In contrast, patients who were randomized to receive UFH plus GPIIbIIIa inhibitors after being treated with a heparin experienced a significant increase in all bleeding events and transfusions (Gibson et al 2007).

\section{Other patient subgroups}

Although beyond the scope of this review, the successful use of bivalirudin in CABG in patients with either HIT/HITTS or a contraindication to protamine use has been reported (Jabr et al 2004; Merry 2004; Merry et al 2004). More specifically, two randomized, multicenter trials compared UFH with protamine reversal to bivalirudin in patients undergoing CABG with or without cardiopulmonary bypass. At 12 weeks follow-up, there were no significant differences in procedural success, mortality, 24-hour blood loss, overall incidence of transfusions, and duration of surgery between the two treatment groups (Dyke et al 2006; Smedira et al 2006).

In addition, the use of bivalirudin during percutaneous peripheral revascularization has been investigated (Eres 2006). A recent small, prospective study has reported acceptable in-hospital and 30-day ischemic and bleeding outcomes in this patient population and clinical setting (APPROVE Trial) (APPROVE 2004).

\section{Impact of anemia, bleeding, and transfusions in ACS}

The presence of anemia in ACS patients may not only be a predictor of an increase the risk of major hemorrhagic complications during PCI but also may be linked to an increase in mortality (Rao et al 2005; Eikelboom et al 2006). Previous studies have shown that anemic patients undergoing PCI were more likely to have in-hospital death (McKechnie et al 2004), composite major adverse cardiac events (Lee et al 2004; McKechnie et al 2004), and higher post-procedure cardiac biomarker release (Lee et al 2004). The occurrence of these hemorrhagic complications was investigated in an analysis over 9,900 patients who underwent PCI. Investigators followed these patients for the incidence of ischemic and bleeding complications by activated clotting time (ACT) quartile. Ischemic endpoints (defined as death, $\mathrm{MI}$, or revascularization at 48 hours) were not correlated with maximal procedural ACT, but higher doses of UFH (>5000 U, or up to $90 \mathrm{U} / \mathrm{kg}$ ) were independently associated with higher rates of events. There was a significant linear relationship between ACT quartile and occurrence of an overall bleeding event (Brener et al 2004).

In regards to use with bivalirudin, evaluation of anemic versus non-anemic patients from another trial suggests that anemic patients undergoing PCI were more likely to be older, non-Caucasian, female gender, of lower body weight, of worse renal function, have previous MI, have prior revascularization (PCI or CABG), and/or present with ACS. In addition, anemic patients were found to have an increased risk of 1-year mortality, major bleeding, and transfusion rate $(4.3 \%$ vs $1.5 \%, 4.9 \%$ vs $2.8 \%, 3.6 \%$ vs $0.7 \%$, respectively). However, there was no increase in rates of ischemic events in the anemic patients $(7.6 \%$ vs $7.3 \%, p=N S)$. When causes of death were investigated in these patients, there was not a preponderance of cardiovascular related (versus non-cardiovascular-related) deaths in the anemic group (Voeltz et al 2007).

In addition, a post-hoc analysis of a more recent larger trial examined the predictors of major bleeding and its impact on 30-day outcomes, including mortality. The study's results showed that patients who were randomized to UFH plus GPIIbIIIa inhibitors had higher major bleeding rates compared to those patients that received bivalirudin alone $(5.7 \%$ vs $3.0 \%, \mathrm{p}<0.001)$. Furthermore, patients with major bleeding had higher 30-day rates of mortality (7.3\% vs $1.2 \%, \mathrm{p}<0.0001)$, composite ischemia $(23.1 \%$ vs $6.8 \%, \mathrm{p}<0.0001)$, and stent thrombosis $(3.4 \%$ vs $0.6 \%$, $\mathrm{p}<0.0001)$ compared to those patients who did not. Of note, patients who had a major bleeding event following PCI had a $>7$-fold times mortality rate than those patients who did not (OR 7.55, CI 4.68-2.18, p < 0.0001), which was a stronger predictor of mortality than peri-procedural MI (Manoukian et al 2007).

Based on these data, baseline anemia and peri-procedural major bleeding events following PCI are a powerful independent predictor of (short-term) mortality in ACS patients who are managed invasively. Therefore, it seems imperative 
that improvements in treatment modalities or antithrombotic medications (eg, DTIs) reduce bleeding rates during and following PCI.

\section{Summary}

In patients presenting with ACS and selected for an early, invasive treatment strategy with cardiac catheterization and subsequent PCI, aggressive antiplatelet and antithrombotic medications are required to avoid worsened ischemic outcomes. But, these potent anticoagulants pose risks of increased bleeding events. Currently, with a number of available anticoagulant medications but inadequate comparative data, there is no recommendation for one preferred regimen in treating ACS patients. However, bivalirudin has several pharmacologic and pharmacodynamic properties that appear advantageous over indirect thrombin inhibitors. Numerous trials regarding USA/NSTEMI patients undergoing PCI have shown that these properties have translated to excellent clinical efficacy including similar rates of ischemic events and lower rates of bleeding when compared to therapy including a heparin plus GPIIbIIIa inhibitors. Therefore, bivalirudin is a safe and effective anticoagulant for use in ACS with PCI. Further (long-term) data are still needed to assess bivalirudin's role in STEMI patients.

\section{Acknowledgments}

The authors would like to thank Dr. John F. Moran, M.D. for his review of this manuscript.

\section{Disclosures}

The authors have no conflicts of interest to disclose.

\section{References}

Anand SX, Kim MC, Kamran M, et al. 2007. Comparison of platelet function and morphology in patients undergoing percutaneous coronary intervention receiving bivalirudin versus unfractionated heparin versus clopidogrel pretreatment and bivalirudin. Am J Cardiol, 100:417-24.

Anderson JL, Adams CD, Antman EM, et al. 2007. ACC/AHA 2007 guidelines for the management of patients with unstable angina/nonST-Elevation myocardial infarction: a report of the American College of Cardiology/American Heart Association Task Force on Practice Guidelines Writing Committee to Revise the 2002 Guidelines for the Management of Patients With Unstable Angina/Non-ST-Elevation Myocardial Infarction. developed in collaboration with the American College of Emergency Physicians, the Society for Cardiovascular Angiography and Interventions, and the Society of Thoracic Surgeons endorsed by the American Association of Cardiovascular and Pulmonary Rehabilitation and the Society for Academic Emergency Medicine. $J$ Am Coll Cardiol, 50:e1-e157.

APPROVE. 2004. The Angiomax Peripheral Procedure Registry of Vascular Events Trial (APPROVE): in-hospital and 30-day results. J Invasive Cardiol, 16, 651-6.

Arora UK, Dhir M. 2005. Direct thrombin inhibitors part 1 of 2.J Invasive Cardiol, 17:34-8.
Bates ER. 2004. Bivalirudin: an anticoagulant option for percutaneous coronary intervention. Expert Rev Cardiovasc Ther, 2:153-62.

Bates SM, Weitz JI. 1998. Direct thrombin inhibitors for treatment of arterial thrombosis: potential differences between bivalirudin and hirudin. Am J Cardiol, 82:12P-18P.

Becker DL, Fredenburgh JC, Stafford AR. et al. 1999. Exosites 1 and 2 are essential for protection of fibrin-bound thrombin from heparincatalyzed inhibition by antithrombin and heparin cofactor II. $J$ Biol Chem, 274:6226-33.

Bittl JA. 1995. Comparative safety profiles of hirulog and heparin in patients undergoing coronary angioplasty. The Hirulog Angioplasty Study Investigators. Am Heart J, 130:658-65.

Bittl JA, Chaitman BR, Feit F, et al. 2001. Bivalirudin versus heparin during coronary angioplasty for unstable or postinfarction angina: Final report reanalysis of the Bivalirudin Angioplasty Study. Am Heart $J$, 142:952-9.

Bittl JA, Strony J, Brinker JA, et al. 1995. Treatment with bivalirudin Hirulog. as compared with heparin during coronary angioplasty for unstable or postinfarction angina. Hirulog Angioplasty Study Investigators. N Engl J Med, 333:764-9.

Brener SJ, Moliterno DJ, Lincoff AM, et al. 2004. Relationship between activated clotting time and ischemic or hemorrhagic complications: analysis of 4 recent randomized clinical trials of percutaneous coronary intervention. Circulation, 110:994-8.

Burke AP, Farb A, Malcom GT, et al. 1998. Effect of risk factors on the mechanism of acute thrombosis and sudden coronary death in women. Circulation, 97:2110-6.

Burke AP, Farb A, Malcom GT, et al. 1997. Coronary risk factors and plaque morphology in men with coronary disease who died suddenly. N Engl J Med, 336:1276-82.

Cairns JA, Gent M, Singer J, et al. 1985. Aspirin, sulfinpyrazone, or both in unstable angina. Results of a Canadian multicenter trial. $N$ Engl J Med, 313:1369-75.

Cannon CP, Maraganore JM, Loscalzo J, et al. 1993. Anticoagulant effects of hirulog, a novel thrombin inhibitor, in patients with coronary artery disease. Am J Cardiol, 71:778-82.

CAPRIE. 1996. A randomised, blinded, trial of clopidogrel versus aspirin in patients at risk of ischaemic events CAPRIE. CAPRIE Steering Committee. Lancet, 348, 1329-39.

Chamberlin JR, Lewis B, Leya F, et al. 1995. Successful treatment of heparin-associated thrombocytopenia and thrombosis using Hirulog. Can J Cardiol, 11:511-4.

Chong BH. 2003. Heparin-induced thrombocytopenia. J Thromb Haemost, 1:1471-8.

Cohen M, Adams PC, Parry G, et al. 1994. Combination antithrombotic therapy in unstable rest angina and non-Q-wave infarction in nonprior aspirin users. Primary end points analysis from the ATACS trial. Antithrombotic Therapy in Acute Coronary Syndromes Research Group. Circulation, 89:81-8.

Da L. 1989. Heparin binding and neutralizing proteins. Boca Raton, CRC Press.

De Romeuf C, Mazurier C. 1993. Heparin binding assay of von Willebrand factor vWF. in plasma milieu - evidence of the importance of the multimerization degree of vWF. Thromb Haemost, 69:436-40.

Di Nisio M, Middeldorp S, Buller HR. 2005. Direct thrombin inhibitors. N Engl J Med, 353:1028-40.

Dyke CM, Smedira NG, Koster A, et al. 2006. A comparison of bivalirudin to heparin with protamine reversal in patients undergoing cardiac surgery with cardiopulmonary bypass: the EVOLUTION-ON study. $J$ Thorac Cardiovasc Surg, 131:533-9.

Eikelboom JW, Mehta SR, Anand SS, et al. 2006. Adverse impact of bleeding on prognosis in patients with acute coronary syndromes. Circulation, 114:774-82.

Eitzman DT, Chi L, Saggin L, et al. 1994. Heparin neutralization by plateletrich thrombi. Role of platelet factor 4. Circulation, 89:1523-9.

Eres A. 2006. Use of bivalirudin as the foundation anticoagulant during percutaneous peripheral interventions. J Invasive Cardiol, 18:125-8. 
Fenton JW 2nd, Ofosu FA, Brezniak DV, et al. 1998. Thrombin and antithrombotics. Semin Thromb Hemost, 2487-91.

Ferguson JJ, Califf RM, Antman EM, et al. 2004. Enoxaparin vs unfractionated heparin in high-risk patients with non-ST-segment elevation acute coronary syndromes managed with an intended early invasive strategy: primary results of the SYNERGY randomized trial. JAMA, 292:45-54.

Fox I, Dawson A, Loynds P, et al. 1993. Anticoagulant activity of Hirulog, a direct thrombin inhibitor, in humans. Thromb Haemost, 69:157-63.

FRISC. 1996. Low-molecular-weight heparin during instability in coronary artery disease, Fragmin during Instability in Coronary Artery Disease FRISC study group. Lancet, 347, 561-8.

Furie B, Furie BC. 1992. Molecular and cellular biology of blood coagulation. $N$ Engl J Med, 326:800-6.

Gibson CM, Morrow DA, Murphy SA, et al. 2006. A randomized trial to evaluate the relative protection against post-percutaneous coronary intervention microvascular dysfunction, ischemia, and inflammation among antiplatelet and antithrombotic agents: the PROTECT-TIMI-30 trial. J Am Coll Cardiol, 47:2364-73.

Gibson CM, Ten Y, Murphy SA, et al. 2007. Association of prerandomization anticoagulant switching with bleeding in the setting of percutaneous coronary intervention A REPLACE-2 analysis. Am J Cardiol, 99:1687-90.

Gurfinkel EP, Manos EJ, Mejail RI, et al. 1995. Low molecular weight heparin versus regular heparin or aspirin in the treatment of unstable angina and silent ischemia. $J$ Am Coll Cardiol, 26:313-8.

Gurm HS, Rajagopal V, Bhatt DL, et al. 2007. The safety of a bivalirudin-based approach in patients undergoing rotational atherectomy. $J$ Invasive Cardiol, 19:225-8.

Hirsh J. 1991. Heparin. N Engl J Med, 324:1565-74.

Hogg PJ, Bock PE. 1997. Modulation of thrombin and heparin activities by fibrin. Thromb Haemost, 77:424-33.

ISIS-2. 1988. Randomised trial of intravenous streptokinase, oral aspirin, both, or neither among 17,187 cases of suspected acute myocardial infarction: ISIS-2. ISIS-2 (Second International Study of Infarct Survival) Collaborative Group. Lancet, 2:349-60.

Jabr K, Johnson J, McDonald MH, et al. 2004. Plasma-modified ACT can be used to monitor bivalirudin Angiomax. anticoagulation for on-pump cardiopulmonary bypass surgery in a patient with heparin-induced thrombocytopenia. Journal of Extra-Corporeal Technology, 36:174-7.

King SB 3rd, Smith SC Jr, Hirshfeld JW Jr, et al. 2007. 2007 Focused Update of the ACC/AHA/SCAI 2005 Guideline Update for Percutaneous Coronary Intervention. A Report of the American College of Cardiology/American Heart Association Task Force on Practice Guidelines. Circulation.

Kumar R, Beguin S, Hemker HC. 1994. The influence of fibrinogen and fibrin on thrombin generation - evidence for feedback activation of the clotting system by clot bound thrombin. Thromb Haemost, $72: 713-21$.

Kumar R, Beguin S, Hemker HC. 1995. The effect of fibrin clots and clotbound thrombin on the development of platelet procoagulant activity. Thromb Haemost, 74:962-8.

Lee PC, Kini AS, Ahsan C, et al. 2004. Anemia is an independent predictor of mortality after percutaneous coronary intervention. $J$ Am Coll Cardiol, 44:541-6.

Lehman SJ, Chew DP. 2006. Bivalirudin in percutaneous coronary intervention. Vasc Health Risk Manag, 2:357-63.

Lewis HD Jr, Davis JW, Archibald DG, et al. 1983. Protective effects of aspirin against acute myocardial infarction and death in men with unstable angina. Results of a Veterans Administration Cooperative Study. N Engl J Med, 309:396-403.

Lidon RM, Theroux P, Juneau M, et al. 1993. Initial experience with a direct antithrombin, Hirulog, in unstable angina. Anticoagulant, antithrombotic, and clinical effects. Circulation, 88:1495-501.

Lincoff AM, Bittl JA, Harrington RA, et al. 2003. Bivalirudin and provisional glycoprotein IIb/IIIa blockade compared with heparin and planned glycoprotein IIb/IIIa blockade during percutaneous coronary intervention: REPLACE-2 randomized trial. JAMA, 289853-63.
Lincoff AM, Bittl JA, Kleiman NS, et al. 2004. Comparison of bivalirudin versus heparin during percutaneous coronary intervention the Randomized Evaluation of PCI Linking Angiomax to Reduced Clinical Events [REPLACE]-1 trial. Am J Cardiol, 93:1092-6.

Lincoff AM, Kleiman NS, Kottke-Marchant K, et al. 2002. Bivalirudin with planned or provisional abciximab versus low-dose heparin and abciximab during percutaneous coronary revascularization: results of the Comparison of Abciximab Complications with Hirulog for Ischemic Events Trial CACHET. Am Heart J, 143:847-53.

Mahaffey KW, Lewis BE, Wildermann NM, et al. 2003. The anticoagulant therapy with bivalirudin to assist in the performance of percutaneous coronary intervention in patients with heparin-induced thrombocytopenia ATBAT. study: main results. J Invasive Cardiol, 15:611-6.

Manoukian SV, Feit F, Mehran R, et al. 2007. Impact of major bleeding on 30-day mortality and clinical outcomes in patients with acute coronary syndromes: an analysis from the ACUITY Trial. $J$ Am Coll Cardiol, 49:1362-8.

Maraganore JM, Bourdon P, Jablonski J, et al. 1990. Design and characterization of hirulogs: a novel class of bivalent peptide inhibitors of thrombin. Biochemistry, 29:7095-101.

McKechnie RS, Smith D, Montoye C, et al. 2004. Prognostic implication of anemia on in-hospital outcomes after percutaneous coronary intervention. Circulation, 110:271-7.

Mehta SR, Yusuf S, Peters RJ, et al. 2001. Effects of pretreatment with clopidogrel and aspirin followed by long-term therapy in patients undergoing percutaneous coronary intervention: the PCI-CURE study. Lancet, 358:527-33.

Merry AF. 2004. Bivalirudin, blood loss, and graft patency in coronary artery bypass surgery. Semin Thromb Hemost, 30:337-46.

Merry AF, Raudkivi PJ, Middleton NG, et al. 2004. Bivalirudin versus heparin and protamine in off-pump coronary artery bypass surgery. Ann Thorac Surg, 77:925-31; discussion 931.

Mirshahi M, Soria J, Soria C, et al. 1989. Evaluation of the inhibition by heparin and hirudin of coagulation activation during r-tPA-induced thrombolysis. Blood, 74:1025-30.

Oler A, Whooley MA, Oler J, et al. 1996. Adding heparin to aspirin reduces the incidence of myocardial infarction and death in patients with unstable angina. A meta-analysis. JAMA, 276:811-5.

Parry MA, Maraganore JM, Stone SR. 1994. Kinetic mechanism for the interaction of Hirulog with thrombin. Biochemistry, 33:14807-14.

Rao SV, O'Grady K, Pieper KS, et al. 2005. Impact of bleeding severity on clinical outcomes among patients with acute coronary syndromes. Am J Cardiol, 96:1200-6.

Reed MD, Bell D. 2002. Clinical pharmacology of bivalirudin. Pharmacotherapy, 22:105S-111S

RISC. 1990. Risk of myocardial infarction and death during treatment with low dose aspirin and intravenous heparin in men with unstable coronary artery disease. The RISC Group. Lancet, 336:827-30.

Robson R. 2000. The use of bivalirudin in patients with renal impairment. J Invasive Cardiol, 12(Suppl F):33F-6.

Rosamond W, Flegal K, Friday G, et al. 2007. Heart disease and stroke statistics - 2007 update: a report from the American Heart Association Statistics Committee and Stroke Statistics Subcommittee. Circulation, 115:e69-171.

Sakharov DV, Plow EF, Rijken DC. 1997. On the mechanism of the antifibrinolytic activity of plasma carboxypeptidase B. J Biol Chem, $272,14477-82$.

Schaar JA, Muller JE, Falk E, et al. 2004. Terminology for high-risk and vulnerable coronary artery plaques. Report of a meeting on the vulnerable plaque, June 17 and 18, 2003, Santorini, Greece. Eur Heart J, 25:1077-82.

Schror K. 1993. The basic pharmacology of ticlopidine and clopidogrel. Platelets, 4:252-61.

Sciulli TM, Mauro VF. 2002. Pharmacology and clinical use of bivalirudin. Ann Pharmacother, 36:1028-41.

Sharma GV, Lapsley D, Vita JA, et al. 1993. Usefulness and tolerability of hirulog, a direct thrombin-inhibitor, in unstable angina pectoris. $\mathrm{Am} \mathrm{J}$ Cardiol, 72:1357-60. 
Shen GX, XM, Fenton JW, et al. 1997. Effect of hirulog-1 on fibrinolysis and platelet deposition abstract. Atherosclerosis, 134:195.

Smedira NG, Dyke CM, Koster A, et al. 2006. Anticoagulation with bivalirudin for off-pump coronary artery bypass grafting: the results of the EVOLUTION-OFF study. J Thorac Cardiovasc Surg, 131, 686-92.

Stella J, Stella D, Iaffaldano R, et al. 2006. The bivalirudin in the management of patients with ST-segment elevation acute myocardial infarction undergoing primary PCI BIAMI. Trial. Society of Cardiovascular Angiography and Interventions.

Stella JF, Stella RE, Iaffaldano RA, et al. 2004. Anticoagulation with bivalirudin during percutaneous coronary intervention for ST-segment elevation myocardial infarction. J Invasive Cardiol, 16:451-4.

Stone GW. 2007. HORIZONS AMI: Bivalirudin reduces bleeding, adverse clinical events in STEMI. TCT. Washington, D.C.

Stone GW, McLaurin BT, Cox DA, et al. 2006. Bivalirudin for patients with acute coronary syndromes. $N$ Engl J Med, 355:2203-16.

Stone GW, Ware JH, Bertrand ME, et al. 2007a. Antithrombotic strategies in patients with acute coronary syndromes undergoing early invasive management: one-year results from the ACUITY trial. JAMA, 298:2497-506.

Stone GW, White HD, Ohman EM, et al. 2007b. Bivalirudin in patients with acute coronary syndromes undergoing percutaneous coronary intervention: a subgroup analysis from the Acute Catheterization and Urgent Intervention Triage strategy ACUITY. trial. Lancet, 369:907-19.

Telford AM, Wilson C. 1981. Trial of heparin versus atenolol in prevention of myocardial infarction in intermediate coronary syndrome. Lancet, $1: 1225-8$.

Theroux P, Ouimet H, McCans J, et al. 1988. Aspirin, heparin, or both to treat acute unstable angina. $N$ Engl J Med, 319:1105-11.

Theroux P, Waters D, Qiu S, et al. 1993. Aspirin versus heparin to prevent myocardial infarction during the acute phase of unstable angina. Circulation, 88:2045-8.

TIMI-8. 2002. Bivalirudin as a replacement for unfractionated heparin in unstable angina/non-ST-elevation myocardial infarction: observations from the TIMI 8 trial. The Thrombolysis in Myocardial Infarction. Am Heart J, 143:229-34.

Topol EJ, Bonan R, Jewitt D, et al. 1993. Use of a direct antithrombin, hirulog, in place of heparin during coronary angioplasty. Circulation, $87: 1622-9$.
Virmani R, Burke AP, Farb A, et al. 2006. Pathology of the vulnerable plaque. $J$ Am Coll Cardiol, 47:C13-8.

Virmani R, Kolodgie FD, Burke AP, et al. 2000. Lessons from sudden coronary death: a comprehensive morphological classification scheme for atherosclerotic lesions. Arterioscler Thromb Vasc Biol, 20:1262-75

Voeltz MD, Patel AD, Feit F, et al. 2007. Effect of anemia on hemorrhagic complications and mortality following percutaneous coronary intervention. Am J Cardiol, 99:1513-7.

Waksman R, Wolfram RM, Torguson RL, et al. 2006. Switching from Enoxaparin to Bivalirudin in Patients with Acute Coronary Syndromes without ST-segment Elevation who Undergo Percutaneous Coronary Intervention. Results from SWITCH - a multicenter clinical trial. J Invasive Cardiol, 18:370-5.

Weitz JI. 1997. Low-molecular-weight heparins. N Engl J Med, 337:688-98. Weitz JI, Hudoba M, Massel D, et al. 1990. Clot-bound thrombin is protected from inhibition by heparin-antithrombin III but is susceptible to inactivation by antithrombin III-independent inhibitors. J Clin Invest, 86:385-91.

Weitz JI, Leslie B, Hudoba, M. 1998. Thrombin binds to soluble fibrin degradation products where it is protected from inhibition by heparin-antithrombin but susceptible to inactivation by antithrombinindependent inhibitors. Circulation, 97:544-52.

White H. 2001. Thrombin-specific anticoagulation with bivalirudin versus heparin in patients receiving fibrinolytic therapy for acute myocardial infarction: the HERO-2 randomised trial. Lancet, 358:1855-63.

Williams DO, Kirby MG, McPherson K. et al. 1986. Anticoagulant treatment of unstable angina. Br J Clin Pract, 40:114-6.

Yusuf S, Mehta SR, Chrolavicius S, et al. 2006a. Comparison of fondaparinux and enoxaparin in acute coronary syndromes. $N$ Engl $J$ Med, 354:1464-76.

Yusuf S, Mehta SR, Chrolavicius S, et al. 2006b. Effects of fondaparinux on mortality and reinfarction in patients with acute ST-segment elevation myocardial infarction: the OASIS-6 randomized trial. JAMA, 295:1519-30.

Yusuf S, Zhao F, Mehta SR, et al. 2001. Effects of clopidogrel in addition to aspirin in patients with acute coronary syndromes without ST-segment elevation. N Engl J Med, 345:494-502. 
